\title{
AVALIAÇÃO DO PISO DE CONCRETO UTILIZADO PARA CAPTAÇÃO DE ÁGUA DA CHUVA EM CISTERNAS- CALÇADÃO
}

\author{
Paulo Roberto Lopes Lima ${ }^{1}$ \\ Cintia Maria Ariani Fontes ${ }^{2}$ \\ Silvaney Santiago Souza ${ }^{3}$ \\ João Antonio S. Pires Coelho ${ }^{4}$
}

\begin{abstract}
Resumo: A cisterna de placas para armazenamento de água da chuva tem sido uma das principais tecnologias sociais utilizadas no semiárido para manutenção do homem no campo, visto que em períodos de seca, e mesmo nos períodos de chuva, é a única fonte de abastecimento de água potável em muitas regiões. A cisterna calçadão disponibiliza água para produção de alimentos e criação animal e complementa a sobrevivência no semiárido ao prover uma alternativa de desenvolvimento econômico No entanto, devido à pouca experiência dos construtores com esse tipo de tecnologia, que seja uma extensa placa de concreto simples apoiada diretamente sobre o solo, muitos dos calçadões construídos tem apresentado problemas de fissuração que limitam a capacidade de captação de água. Este trabalho tem como objetivo a avaliação do processo construtivo e caracterização do concreto utilizado na produção de calçadões com vistas a melhoria da sua qualidade. Foram realizados visitas in loco com monitoramento da construção e coleta de amostras dos materiais utilizados para caracterização em laboratório. Corpos de prova de concreto foram moldados para determinação da resistência mecânica e absorção de água. Os resultados indicam que o concreto apresentou resistência à compressão muito baixa e, com isso, torna-se necessário a melhoria no processo construtivo para garantir um calçadão com maior resistência e durabilidade.
\end{abstract}

Palavras-Chave: piso de concreto; cisterna; durabilidade,processo construtivo; semiárido.

Abstract: Tanks for storage of rain water has been a major social technologies used in the semiarid maintenance man in the field. In periods without rain it is the only source of drinking water supply in many regions. The cistern provides water for food production and animal husbandry allowing survival in semiarid. However, many floors used for collecting rainwater have presented problems of cracking. The objective of this work is to identify and characterize the constructive process used in producing these concrete floors. Were conducted on-site visits to construction monitoring and sampling of materials with determination of mechanical strength and water absorption of concrete in laboratory. The results indicate the need for improvement in the process and dosage of concrete to ensure a floor with greater strength and durability.

Keywords: concrete floor; durability; rainwater, constructive method; semiarid.

\footnotetext{
${ }^{1}$ Programa de Pós-graduação em Engenharia Civil e Ambiental - PPGECEA, Universidade Estadual de Feira de Santana - UEFS. E-mail: lima.prl@pq.cnpq.br.

${ }^{2}$ Programa de Pós-graduação em Engenharia Civil e Ambiental - PPGECEA, Universidade Estadual de Feira de Santana - UEFS. E-mail: cintiafontes@gmail.com.

${ }^{3}$ APAEB Serrinha. E-mail: toledo@coc.ufrj.br.

4 , Departamento de Tecnologia, Universidade Estadual de Feira de Santana - UEFS, Av. Transnordestina, SN. E-mail: joao_aspc@hotmail.com.
} 


\section{INTRODUÇÃO}

O aproveitamento de água da chuva é uma técnica antiga, e o seu armazenamento constitui, muitas vezes, a única fonte de suprimento de água para consumo humano e uso doméstico em muitas regiões rurais, sem acesso à rede pública de fornecimento de água potável. Nos Estados Unidos a captação sistemática de água da chuva para abastecimento de escolas rurais ou para uso em fazendas já existe desde 1914, tanto para consumo humano como para atividades de limpeza e agricultura (Trullinger, 1914; Evans, 1914). No entanto, de acordo com Boers (1994), sistemas modernos de captação e manejo de água da chuva só foram implantados a partir de 1955.

Durante as últimas décadas, devido ao seu baixo custo e simplicidade tecnológica para implantação, vários sistemas de captação e armazenamento de água da chuva têm sido utilizados em regiões áridas e semiáridas do mundo, com o objetivo de garantir condições mínimas de sustentabilidade da população. Além da água para consumo doméstico, tais sistemas têm permitido a utilização de água da chuva também para agricultura e criação animal.

No aproveitamento de águas pluviais, dois processos básicos são importantes: um é a captação e distribuição do escoamento superficial e o outro é o armazenamento e conservação de água. $\mathrm{O}$ sistema de captação mais usual de água para consumo humano tem sido o telhado das edificações rurais. Para criação animal ou manutenção de pequenas lavouras, um maior volume de água é necessário e outros sistemas de captação tem sido utilizados, onde a água é transportada por gravidade (UNEP, 2012). No Brasil, um modelo de cisterna, denominado CPATSA, foi desenvolvido pela EMBRAPA (1984) utilizando o próprio solo, que pode ser protegido por gramínea ou lona plástica, para captação de água da chuva. Esse sistema foi amplamente empregado no Nordeste brasileiro e mesmo em outros países
(Oosterbaan; Martinez, 1987).

Desde 2007, o Programa P1+2 (1 Terra +2 Águas) implementa no semiárido brasileiro um tipo de cisterna, denominado cisterna-calçadão, que tem como função garantir a captação de grande volume de água, 53 mil litros, com o objetivo de prover água para hortas e criação animais (DIACONIA, 2008). Nessas cisternas, diferentemente do sistema já utilizado com coleta pelo telhado da edificação, o sistema de captação é formado por um calçadão de argamassa ou concreto simples, de cerca de $210 \mathrm{~m}^{2}$, construído dentro de uma parede de alvenaria de blocos e tendo uma inclinação para escoamento da água da chuva (ASA, 2013). A água captada escoa por gravidade até uma cisterna construída com placas de argamassa e instalada enterrada em uma das suas extremidades, como mostra a Figura 1a.

A utilização deste tipo de cobertura, em piso de concreto, apresenta grande potencial de captação de água, sendo, mas eficiente que a cobertura em rocha natural ou solo batido e compatível com cobertura metálica (Naggar, 2006; Mendez et al, 2011). Seu uso é recomendado pelo "Projeto 121", desenvolvido na Província chinesa de Gansu para convivência com o semiárido, e já resultou em aceleração do progresso econômico daquela região (Zhu et al., 2004).

No Brasil, no entanto, tanto a cisterna de argamassa quanto o calçadão de concreto tem apresentado problemas estruturais que reduzem, ou mesmo impedem, a captação e armazenamento adequado de água, como mostra a Figura 1b. Com isso, além da perda de funcionalidade da estrutura, que deixa de contribuir para fomentar a sede da população do semiárido, as patologias identificadas colocam em xeque a qualidade das tecnologias, como uma solução adequada para a convivência com a seca no semiárido brasileiro, e a manutenção do seu financiamento (TCU, 2010).

A importância econômica da cisterna calçadão para a sociedade pode ser 
medida não apenas pelo impacto para as pessoas atendidas, mas pela dimensão do volume de material utilizado e comercializado na região. Desde que surgiu, em 2007, até maio de 2013, o P1+2 já construiu 13 mil cisternascalçadão (http://www.asabrasil.org.br/). Como a fabricação do calçadão consome cerca de $8,4 \mathrm{~m}^{3}$ de concreto, isso implica na produção de $109200 \mathrm{~m}^{3}$ de concreto apenas para o calçadão. Considerando também a fabricação da cisterna de placas de 52 mil litros, utilizada para o armazenamento de água, o consumo de materiais foi da ordem de 58 mil toneladas de cimento, 65 mil metros cúbicos de brita e 273 mil metros cúbicos de areia.

Uma primeira avaliação de cisternas calçadão existentes, inclusive com monitoramento da sua construção, indicou a necessidade de mudança na configuração da estrutura do piso (Lima et al., 2012) devido à grande incidência de fissuras. Como solução foi proposto um novo processo de fabricação, com a construção de placas isoladas de concreto, depois rejuntadas com argamassa, em contraposição ao sistema antigo que desenvolvia uma placa continua de concreto, separadas por juntas plásticas de dilatação que nem sempre apresentavam espaçamento correto ou continuidade. $\mathrm{O}$ acompanhamento desse novo processo de construção demonstra, no entanto, que novas melhorias precisam ainda ser aplicadas para garantir a qualidade de longo prazo do calçadão.

O objetivo deste trabalho é apresentar como a tecnologia social de captação de água da chuva, sob a forma de piso de concreto, tem sido construída, indicando as principais patologias, a nova forma de construção e as possíveis melhorias que devem ser implementadas. Visitas de campo foram realizadas para identificação do método de produção e dosagem do concreto utilizado. Amostras de concreto foram coletadas e avaliadas quanto a resistência à compressão e absorção de água.

\section{MATERIAIS E MÉTODOS}

\subsection{VISITAS}

Foram realizadas, junto com a Equipe da APAEB e Articulação do Semiárido (ASA), visitas a cisternas construídas nos municípios de Retirolândia e Serrinha, na Bahia, e o acompanhamento da construção de uma cisterna no município de Retirolândia.

Foi realizado registro fotográfico e entrevista com os pedreiros responsáveis pela construção. Não houve qualquer intervenção da equipe durante o processo de produção que modificasse o método ou o material empregado.

\subsection{AVALIAÇÃO DOS MATERIAIS}

Os materiais componentes do concreto foram coletados e caracterizados em laboratório. $\mathrm{O}$ agregado miúdo utilizado apresentou módulo de finura de $2,77 \mathrm{~mm}$, massa específica de $2,44 \mathrm{~g} / \mathrm{cm}^{3}$ e massa unitária de $1,55 \mathrm{~g} / \mathrm{cm}^{3}$. O agregado graúdo foi uma brita granítica com módulo de finura de $12,5 \mathrm{~mm}$, massa específica de $2,68 \mathrm{~g} / \mathrm{cm}^{3}$ e massa unitária de $1,51 \mathrm{~g} / \mathrm{cm}^{3} \mathrm{O}$ cimento utilizado foi $\mathrm{CP}$ II $-\mathrm{Z}-32$, com massa específica de 2,86 $\mathrm{g} / \mathrm{cm}^{3}$ e massa unitária de $1,42 \mathrm{~g} / \mathrm{cm}^{3}$. Foi realizada a medição da quantidade de materiais secos para determinação do traço

O concreto produzido em campo foi avaliado através do ensaio de abatimento e de ensaios mecânicos (NBR 5739/1994), de resistência à compressão e resistência à tração por compressão diametral, e ensaio de absorção de água (NBR 9778/2005). Corpos de prova cilíndricos, com $100 \mathrm{~mm}$ de diâmetro e $200 \mathrm{~mm}$ de altura, foram moldados no campo (Figura 2a) e colocados à sombra sob lona plástica (Figura 2b). Após 24 horas os corpos de prova foram desmoldados e levados para cura em água, em laboratório. Os ensaios foram realizado após 28 dias

Para avaliação do teor de água, um novo concreto foi moldado em laboratório, com material, trabalhabilidade e traço similares aos obtidos no campo. As mesmas 
propriedades físicas e mecânicas foram

avaliadas.

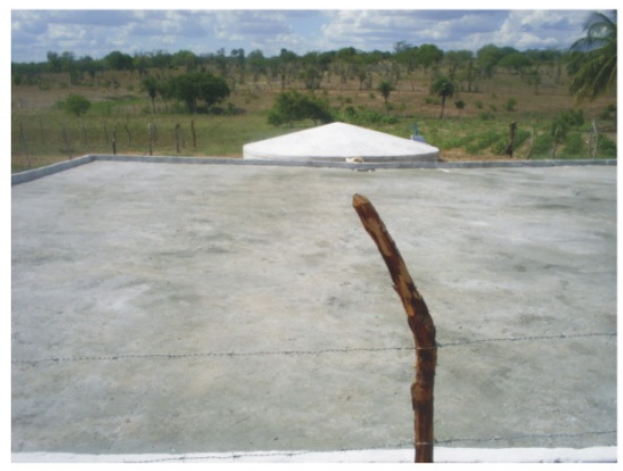

a)

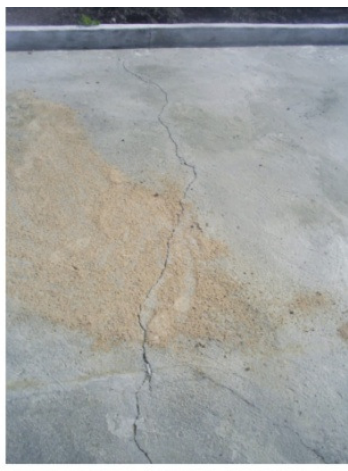

b)

Figura 1. Calçadão de concreto para captação de água da chuva: a) vista geral; b) fissuração do concreto

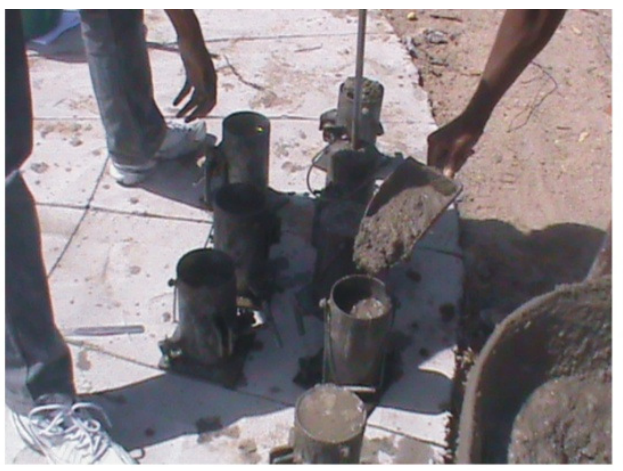

a)

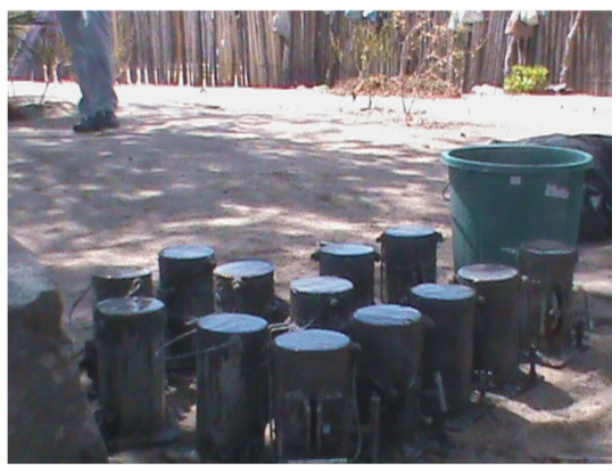

b)

Figura 2. Concreto moldado em campo: a) moldagem e b) cura dos corpos de prova

\section{RESULTADOS E DISCUSSÃO}

\subsection{PROCESSO CONSTRUTIVO DO PISO}

O sistema de construção do piso de concreto para captação de água da chuva na região estudada era, até o ano de 2011, caracterizado pela produção de um piso único de concreto separado por juntas plásticas de separação, como pode ser observado na Figura 3a. Após o surgimento de vários problemas patológicos no calçadão, foi realizada uma avaliação (Lima et al., 2012) que identificou que os principais problemas estruturais estavam relacionados à pouca espessura do calçadão, utilização de aterro na base e falta de continuidade ou inexistência das juntas de dilatação.

Após apresentação e discussão desses problemas em uma Oficina de Avaliação das Implementações, realizada pela Articulação do Semiárido em Surubim-PE, em 2011, foi concebida uma nova forma de construção do calçadão (ASA, 2013). A principal modificação do sistema construtivo foi a substituição do calçadão em piso único para um calçadão formado por placas isoladas de concreto (Figura 3b), rejuntadas posteriormente com argamassa, Figura 3c. O molde da placa é feito em madeira com dimensões 100,0 x 101,5 x 4,0 (largura X comprimento $\mathrm{x}$ altura), que resulta em placas com, aproximadamente, $1 \mathrm{~m}^{2}$. Medidas realizadas em campo indicaram uma espessura de junta de $4 \pm 1 \mathrm{~cm}$.

As vantagens associadas ao novo processo são: i) garantia da espessura do piso: uma vez que a forma tem dimensões padronizadas todas as placas possuirão a mesma espessura que, para o piso monitorado, foi de $3 \mathrm{~cm}$; ii) garantia da existência de juntas de dilatação: enquanto no sistema antigo as juntas eram inexistentes ou sem continuidade, o 
novo sistema garante a sua existência e padroniza a espessura da junta. Ao substituir a junta plástica por outra de argamassa, o método foi adaptado à capacitação técnica do pessoal envolvido na construção; iii) rapidez de execução: antigamente, devido à dificuldade na colocação das juntas de dilatação e os cuidados no transporte do concreto para que as mesmas não fossem descoladas ou danificadas pelo carro de mão, o processo construtivo era lento e descontínuo, originando juntas frias no piso de concreto.

A avaliação de alguns calçadões, construídos na microrregião de Feira de Santana, demonstrou o sucesso da nova técnica visto que os problemas antigos de fissuração não foram identificados. No entanto, apesar das vantagens descritas com a modificação da estrutura do calçadão, foram identificados dois problemas no processo de produção que poderão resultar em patologias futuras no calçadão: falta de alinhamento na moldagem das placas e má produção do concreto.

A contratação dos construtores é feita por cisterna produzida e, devido a isso, o processo construtivo, em alguns casos, é feito, por questões econômicas, o mais rápido possível, mesmo que isso implique em perda de qualidade das cisternas. Apesar da padronização do tamanho da placa e instruções sobre a espessura da junta, foi verificado que o alinhamento das placas não era seguido, como mostra a Figura 4a, o que resultou em descontinuidade das juntas de dilatação e o surgimento de juntas de grande espessura, como pode ser visto na Figura 4b. Verificou-se também que, após a produção de placas em uma parte do calçadão, o concreto passou a ser produzido sobre elas, o que resultou no preenchimento das juntas com o mesmo concreto, e não com argamassa como é previsto. Devido a isso as juntas de dilatação deixaram de existir.

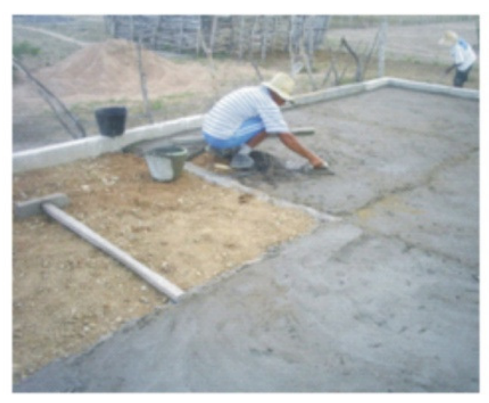

a)

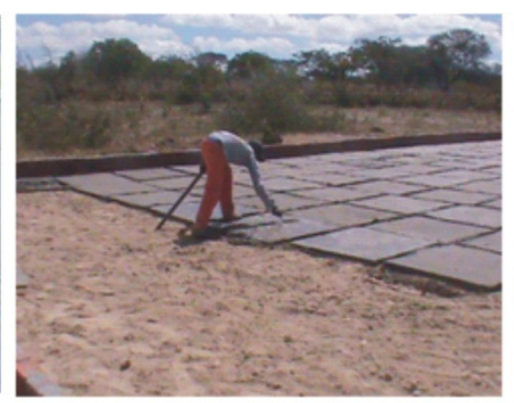

b)

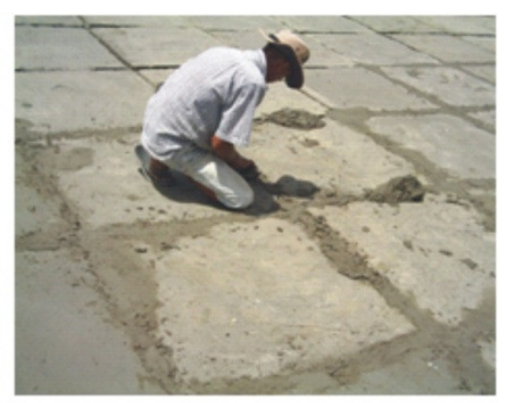

c)

Figura 3. Produção de calçadão de concreto: a) Utilizando junta de dilatação; b) Utilizando placas de concreto; c) rejunte das placas

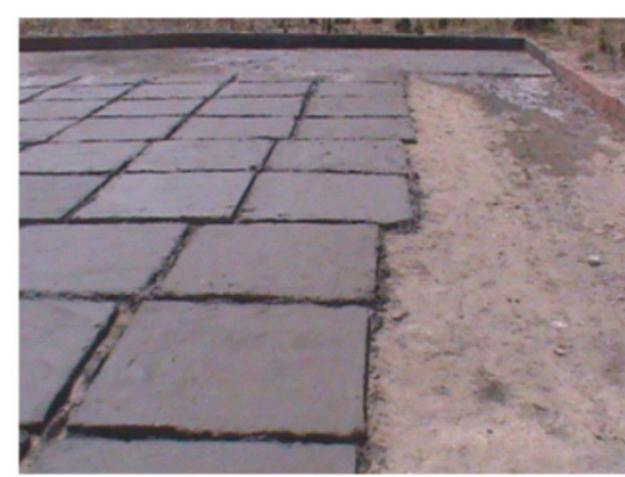

a)

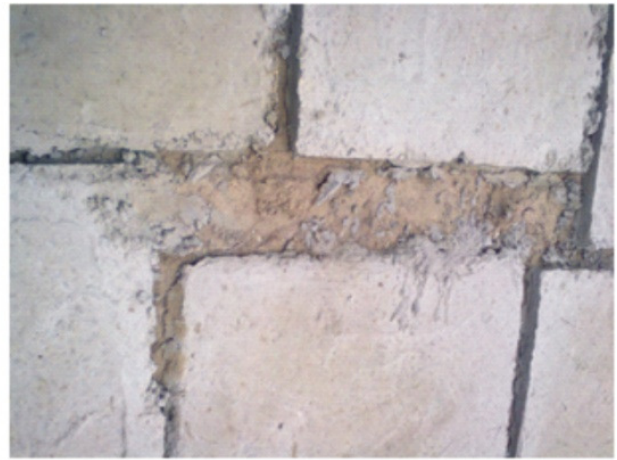

b)

Figura 4. Problemas na produção do calçadão de placas: a) desalinhamento; b) aumento das juntas 


\subsection{PRODUÇÃO DO CONCRETO}

A produção do concreto é caracterizada pela mistura manual, em regime de mutirão, com dosagem dos agregados em volume de carro de mão, para cada saco de cimento $(50 \mathrm{~kg})$ adicionado. A Figura 5 mostra o processo de produção do concreto.

Durante o monitoramento in loco foi verificado que o concreto produzido não apresenta homogeneidade em função do grande volume de concreto produzido para uma mistura manual. Devido a baixa capacitação da equipe, o processo de mistura é desordenado: parte do concreto é retirada da masseira antes que toda a mistura tenha sido produzida, não havendo garantia de que o traço do concreto seja mantido em todas as placas. O transporte do concreto e o lançamento nos moldes da placa são feitos por carro de mão, como mostra a Figura 5c.

O levantamento do traço identificou uma proporção, em volume, de 1: 5,50 : 2,58 (cimento : areia : brita). A quantidade de água não é medida sendo adicionada após a mistura dos materiais secos até que a massa de concreto fique fácil de ser trabalhada com pás e enxadas. Isso resulta em um excesso de água, que pode ser avaliado pelo alto valor do abatimento $(200 \mathrm{~mm})$ e pela grande exsudação de água verificada nos corpos de prova moldados.

A estimativa real do teor de água da mistura foi realizada em laboratório através da moldagem de uma nova mistura. Utilizou-se mesma proporção de materiais secos e materiais de mesma característica que aqueles utilizados em campo. A mistura foi realizada de forma manual e o abatimento foi mantido. $\mathrm{O}$ fator água-cimento obtido foi de 1,29.

Os resultados dos ensaios físicos e mecânicos dos concretos encontram-se na Tabela 1. O coeficiente de variação está apresentado entre parênteses. Verifica-se que o alto valor de absorção de água não é compatível com uma estrutura para captação e transporte de água da chuva, reduzindo a eficiência do calçadão. Os valores de resistência mecânica não são suficientes para garantia da durabilidade do calçadão de concreto ao longo da sua vida útil, pois a baixa resistência á tração favorece a fissuração do calçadão e o desgaste por abrasão devido às partículas sólidas depositadas pelo vento e transportadas pela água da chuva.

$\mathrm{O}$ principal fator a influenciar as propriedades físicas e mecânicas do concreto é o elevado fator água-cimento, que é função do método de mistura manual utilizado. $\mathrm{O}$ grande volume de concreto produzido resulta em uma grande heterogeneidade do material, o que pode ser medido pelos coeficientes de variação das propriedades do concreto produzido em campo, e indicados na Tabela 1, e pode ser comprovado pela avaliação da superfície de ruptura do corpo de prova desse concreto, mostrada na Figura 6, onde a presença de poucos grãos de agregado graúdo é identificada.

Para o concreto produzido em laboratório, com mesmo fator águacimento, foram obtidos valores similares de índice de vazios e absorção, uma redução de $8 \%$ na massa específica mas maiores valores de resistência mecânica, devido a sua melhor homogeneização.

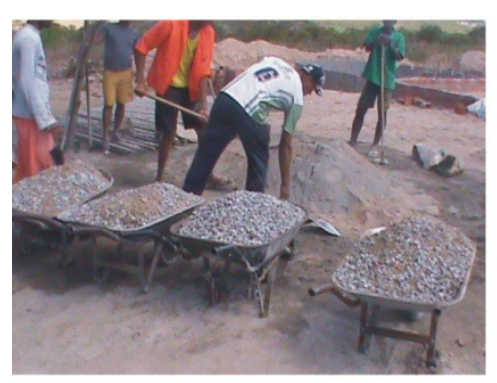

a)

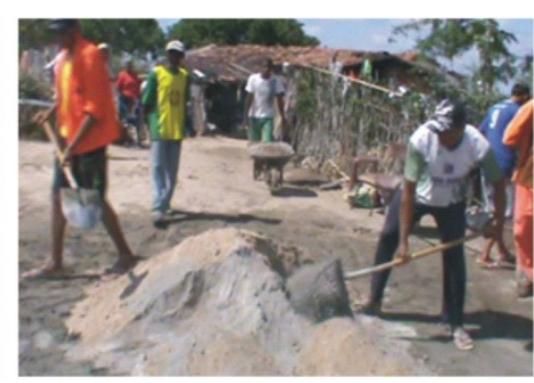

b)

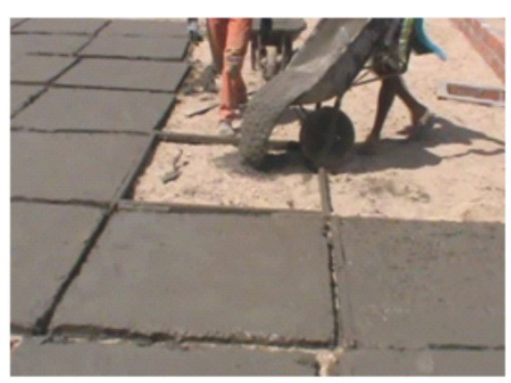

c)

Figura 5. Produção do concreto: a) dosagem em volume; b) mistura manual; c) lançamento 
Tabela 1. Propriedades do concreto (coeficiente de variação, em \%, entre parênteses).

\begin{tabular}{ccc}
\hline Propriedades & $\begin{array}{c}\text { Concreto produzido } \\
\text { em campo }\end{array}$ & $\begin{array}{c}\text { Concreto produzido em } \\
\text { laboratório }\end{array}$ \\
\hline Índice de vazios (\%) & Propriedades físicas & \\
\hline Absorção(\%) & $24,02(6,7)$ & $24,12(0,7)$ \\
\hline Massa específica $\left(\mathrm{g} / \mathrm{cm}^{3}\right)$ & $12,03(8.7)$ & $12,14(0,6)$ \\
\hline Resistência a compressão (MPa) & $2,16(7.6)$ & $4,6(1,6)$ \\
\hline $\begin{array}{c}\text { Resistência a tração por } \\
\text { compressão diametral (MPa) }\end{array}$ & $2,2(27.6)$ & $2,1(14,2)$ \\
\hline
\end{tabular}

O valore de resistência à compressão do concreto moldado em campo é 53\% menor do que o concreto moldado em laboratório, para o mesmo traço. Para a resistência à tração essa redução foi de $47 \%$. Isso indica que o processo de produção precisa ser melhorado, notadamente quanto a forma de mistura dos materiais.

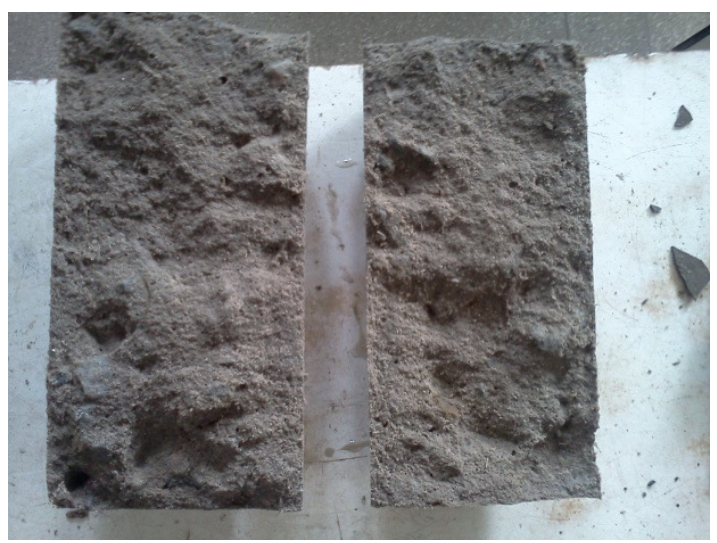

Figura 6. Superfície de ruptura por compressão diametral do concreto moldado em campo

\subsection{PROCESSO CONSTRUTIVO DO PISO}

Estruturalmente o calçadão se comporta como um piso de concreto, ou seja, uma placa totalmente apoiada sob base elástica. No entanto, como sua função é captar água da chuva e conduzila até a cisterna, as ações verticais são mínimas em comparação com as ações oriundas do fluxo de água sobre a sua superfície e as ações resultantes da variação térmica e da variação da umidade do ambiente. Devido a isso, o calçadão de concreto está sujeito ao surgimento de dois tipos de patologia: desgaste superficial por abrasão e fissuração.

A fissuração ocorre, basicamente, quando a resistência à tração do concreto é excedida. Várias são as situações em que isto acontece nas estruturas de concreto, sendo que aquelas oriundas de ações físicas são variação de volume, variação de temperatura e ação de agentes externos. A magnitude das tensões de tração é influenciada pela combinação de diversos fatores, incluindo a intensidade da retração, o grau da restrição, o módulo de elasticidade e a intensidade da fluência (ACI COMMITTEE 224, 1984).

\section{a) Abrasão}

Devido à sua função principal, o calçadão está propenso a abrasão que é originada pela ação de fluidos, contendo partículas sólidas em suspensão, sobre a superfície do concreto. Geralmente é caracterizada por ações de atrito e raspagem e atinge principalmente as estruturas hidráulicas, como barragens, canais, túneis e apoio de pontes.

A taxa de abrasão dependerá da porosidade ou resistência do concreto e da quantidade, tamanho, forma, dureza e velocidade das partículas, sendo que qualquer tipo de concreto, por mais resistente que seja, não consegue suportar 
a abrasão por muito tempo sem apresentar desgaste superficial.

Concretos com maior resistência e agregados duros e densos resistem bem a abrasão (Paulon, 1986). Dessa forma, para que o concreto do calçadão possa resistir ao desgaste superficial gerado pela abrasão é preciso uma maior resistência mecânica e aumento no teor de brita da mistura.

\section{b) Fissuração por variação de volume}

A variação de volume de um elemento de concreto não causa, por si só, danos prejudiciais à estrutura. Mas, como os elementos estão ligados entre si, há o surgimento de restrições de um elemento para outro que impedem a livre expansão ou retração, gerando tensões que causam fissuras. As fissuras podem, então, ser geradas por retração por secagem ou retração plástica do concreto.

A retração por secagem pode ser reduzida através do controle da execução da estrutura, principalmente na produção do concreto. Os fatores que mais a influenciam são o teor de cimento, tipo de agregado, quantidade de água e proporção da mistura (ACI COMMITTEE 224, 1990). A retração plástica ocorre devido à rápida evaporação de água na superfície do concreto, e é influenciada pela temperatura ambiental, umidade relativa do ar, temperatura da superfície do concreto e da velocidade do vento (Ripper, 1986).

Devido ao grande teor de água da mistura do concreto e pequena proporção de agregados graúdos, verifica-se uma grande tendência de variação volumétrica das placas de concreto do calçadão, com o surgimento de fissuras devido à retração, como mostra a Figura 7. As fissuras de retração (ligadas à execução) usualmente correspondem a 95\% das fissuras atualmente encontradas nos pisos de concreto.

\section{c) Fissuração por tensões térmicas}

As fissuras de origem térmica podem surgir por movimentações diferenciadas de calor entre os componentes de um elemento, entre elementos de um sistema ou entre regiões distintas de um mesmo material, e ocorrem em função de (Thomaz, 1989): junção de materiais com diferentes coeficientes de dilatação; exposição de elemento a diferentes temperaturas; ou gradiente de temperatura ao longo do elemento.

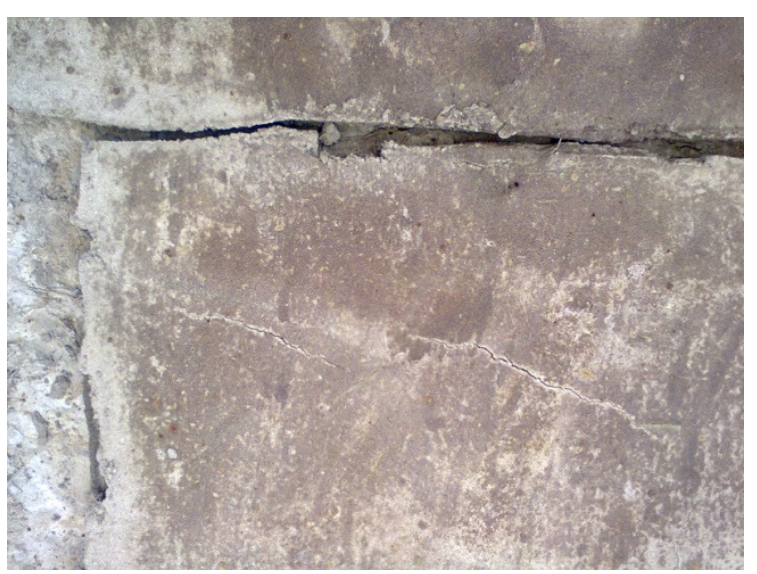

Figura 7. Fissura por retração em placa de concreto do calçadão

A colocação de juntas de dilatação nos elementos estruturais de grande comprimento é a forma utilizada de prevenir a fissuração causada por este processo. De maneira simples, as juntas são criadas com a intenção de permitir a livre movimentação da placa, evitando fissuras e trincas decorrentes de tensões durante o processo de retração do concreto, dilatação e ou cargas atuantes na estrutura.

Juntas de controle agem para aliviar tensões advindas das retrações iniciais do concreto por cura e mudanças térmicas e, quando espaçadas corretamente, reduzem a possibilidade de fissuras ao acaso, sendo, por isso, importante que se mantenha o alinhamento das placas do calçadão. Isso não foi observado em algumas cisternas-calçadão visitadas.

\section{CONCLUSÕES}

Os resultados obtidos após monitoramento da construção do calçadão de concreto em campo e análise dos materiais em laboratório permitiram chegar às seguintes conclusões:

- O processo produtivo do calçadão, com mistura manual do concreto e em regime de mutirão tem contribuído 
para a má homogeneização da mistura, o que resulta na produção de placas com propriedades diferentes em um mesmo calçadão;

- O traço do concreto é inadequado, notadamente na proporção brita/areia. Uma maior quantidade de brita na mistura resultaria em um concreto com maior estabilidade dimensional e, consequentemente, com menor variação volumétrica devido a variações de umidade e temperatura;

- O teor de água é excessivo (fator água/cimento $=1,29$ ) resultando em baixíssima resistência à compressão e à tração o que favorece o surgimento de fissuras nas placas. Além disso, a alta absorção de água do concreto não é adequada para uma estrutura que se propõe a captar água da chuva e transportá-la para armazenamento em cisterna;

- A utilização de pequenas betoneiras elétricas seria mais adequada, não apenas para garantir a melhor homogeneidade da mistura, quanto para reduzir a quantidade de água, visto que o alto teor empregado é devido à dificuldade de mistura manual;

- A produção do calçadão com placas de concreto e juntas de argamassa inibiu a formação de grandes fissuras, como as já observadas em calçadões mais antigos.

\section{AGRADECIMENTOS}

Os autores agradecem ao apoio financeiro do $\mathrm{CNPq}$ (Processo 310807/2010-7), MEC e CAPES.

\section{REFERÊNCIAS}

ACI COMMITTEE 224. 1984. ACI 2241R - Causes, evaluation, and repairs of cracks in concrete structures, $A C I$ Journal, may/june.

ACI COMMITTEE 224. 1990. ACI 224R - Control of cracking in concrete structures, Manual of Concrete Practice.

ASA - ARTICULAÇÃO DO

SEMIÁRIDO. 2013. Cisterna-calçadão. Disponível http://www. youtube.com/watch?v=6BXS jXwvCkE., Acessado em 2013

BOERS, TH. M. 1994. Rainwater harvesting in arid and semi-arid zones, International Institute for Land Reclamation and Improvement, The Netherlands.

DIACONIA. 2008. Cisterna Calçadão 52.000 litros: Série Compartilhando Experiências, Recife: Diaconia, 49p.

EVANS, W. M. P. 1914. Plans for school improvement in village and rural communities, Jefferson City, Missoury, State Department of Education.

LIMA, P. R. L. ; SOUZA, S. S. Diagnóstico de Patologias em calçadão de concreto utilizado para captação de água da chuva e alternativa de solução. $8^{\circ}$ Simpósio Brasileiro de Captação e Manejo de Água da Chuva, 2012, Campina Grande. Brasil, 1-12.

MENDEZ, C. B., KLENZENDORF, J.B., AFSHAR, B.R., SIMMONS, M.T., BARRETT, M.E., KINNEY, K.A., KIRISITS, M.J. 2011. The effect of roofing material on the quality of harvested Rainwater. Water research. 45, 2049-2059.

NAGGAR, O.M. 2012. Rural rainwater harvesting: concepts, techniques and social \& economics impacts. 2006. 6p. Disponivel em: http://ipac.kacst.edu.sa/edoc/2006/15717 6_1.pdf. Acesso em 15 de junho de 2012.

OOSTERBAAN, A.W.A., MARTINEZ, J.V. 1987. Cisternas rurales tipoCPATSA: um manual para su dimensionamiento, constrccion, $y$ mantenimento en El Chaco Central, Paraguay, Departamento de Água para El Chaco.

PAULON, V.A. 1986. Durabilidade dos concretos. In: II Seminário Nordestino sobre Tecnologia do Concreto, Associação Brasileira de Cimento Portland e Instituto Brasileiro de Concreto, Fortaleza. 
RIPPER, E. 1984. Como evitar erros na construção, São Paulo : Pini.

THOMAZ, E. 1989. Trincas em edifícios : causas, prevenção e recuperação, São Paulo : Pini : Escola Politécnica da Universidade de São Paulo, Instituto de Pesquisas tecnológicas.

TRIBUNAL DE CONTAS DA UNIÃO (TCU). 2010. Relatório de auditoria operacional na ação de construção de cisternas para armazenamento de água$2^{\circ}$ monitoramento: $\mathrm{TC} \mathrm{n}^{\circ} 027.314 / 2009-$ 5. $54 \mathrm{p}$.

TRULLINGER, R. W. 1914. Clean water and how to get it on the farm, Department of Agriculture.

\section{UNITED NATIONS ENVIRONMENT} PROGRAMME (UNEP). 2102. Sourcebook of Alternative Technologies for Freshwater Augumentation in Some Countries in Asia. Disponivel em http://www.unep.or.jp/ietc/Publications/te chpublications/TechPub-

8e/rainwater1.asp. Acesso: 16 de junho de 2012.

ZHU, K., ZHANG, L., HART, W. LIU, M., CHEN, H. 2004. Quality issues in harvested rainwater in arid and semi-arid Loess Plateau of northern China. Journal of Arid Environments 57, 487-505. 